Pediatric Injury Biomechanics 

Jeff R. Crandall $\cdot$ Barry S. Myers $\cdot$ David F. Meaney Salena Zellers Schmidtke

Editors

\section{Pediatric Injury Biomechanics}

Archive \& Textbook

Foreword by Stephen A. Ridella

粤 Springer 


\section{Editors}

Jeff R. Crandall, PhD

Department of Biomedical Engineering

University of Virginia

Charlottesville, VA, USA

David F. Meaney, $\mathrm{PhD}$

Department of Bioengineering

University of Pennsylvania

Philadelphia, PA, USA
Barry S. Myers, MD, PhD, MBA

Department of Biomedical Engineering

Duke University

Durham, NC, USA

Salena Zellers Schmidtke, MS, BME

The Southern Consortium for

Injury Biomechanics

Alexandria, VA, USA

ISBN 978-1-4614-4153-3

ISBN 978-1-4614-4154-0 (eBook)

DOI 10.1007/978-1-4614-4154-0

Springer New York Heidelberg Dordrecht London

\section{Library of Congress Control Number: 2012942797}

CC Springer Science+Business Media New York 2013

This work is subject to copyright. All rights are reserved by the Publisher, whether the whole or part of the material is concerned, specifically the rights of translation, reprinting, reuse of illustrations, recitation, broadcasting, reproduction on microfilms or in any other physical way, and transmission or information storage and retrieval, electronic adaptation, computer software, or by similar or dissimilar methodology now known or hereafter developed. Exempted from this legal reservation are brief excerpts in connection with reviews or scholarly analysis or material supplied specifically for the purpose of being entered and executed on a computer system, for exclusive use by the purchaser of the work. Duplication of this publication or parts thereof is permitted only under the provisions of the Copyright Law of the Publisher's location, in its current version, and permission for use must always be obtained from Springer. Permissions for use may be obtained through RightsLink at the Copyright Clearance Center. Violations are liable to prosecution under the respective Copyright Law.

The use of general descriptive names, registered names, trademarks, service marks, etc. in this publication does not imply, even in the absence of a specific statement, that such names are exempt from the relevant protective laws and regulations and therefore free for general use.

While the advice and information in this book are believed to be true and accurate at the date of publication, neither the authors nor the editors nor the publisher can accept any legal responsibility for any errors or omissions that may be made. The publisher makes no warranty, express or implied, with respect to the material contained herein.

Printed on acid-free paper

Springer is part of Springer Science+Business Media (www.springer.com) 


\section{Foreword}

Since the beginning of the new millennium, most developed countries have experienced remarkable reductions in injuries and fatalities resulting from motor vehicle crashes. In presentations made during the 22nd International Technical Conference on the Enhanced Safety of Vehicles, June 13-16, 2011, Washington, DC, representatives of governments from throughout the world reported $25-50 \%$ reductions in motor vehicle crash-related fatalities since the year 2000. Numerous factors are responsible for these reductions. They include but are not limited to cultural and legislative reforms targeting driving, regulatory pressures, improved vehicle technology, and global economic conditions. Despite these hard-fought, impressive improvements in vehicle safety, motor vehicle crashes continue to be a major public health concern, particularly for children. In the most recent available data, the Centers for Disease Control and Prevention posited that motor vehicle crashes are the leading cause of unintentional injury deaths for children 5-14 years of age and the second leading cause of death of unintentional injury deaths for children less than 4 years of age. Nonfatal injury risk is low for children compared to adults, but the fact remains that over 100,000 children under 14 years of age are treated for motor vehicle crashrelated injuries each year.

Statistics of this magnitude reflect not only the scope and impact of pediatric injury in the motor vehicle crash environment but also provided much of the impetus for this project. The automotive safety community treats the issue of child occupant protection very seriously. The Southern Consortium for Injury Biomechanics recognized the opportunity to bring together a unique group of expert injury biomechanists to create a living laboratory of injury data, anthropometry, and biomechanical test data with the capacity to provide state-of-the-art pediatric knowledge. From head to toe, each chapter provides the most current information on pediatric response to deceleration and impact events. Such data that will promote and facilitate development of better child crash test dummies and more accurate child computer models. Better and more "life-like" biofidelic test tools will permit vehicle and child seat manufacturers to design and construct even safer environments for children, and ultimately, reduce the incidence of death and injury for children involved in motor vehicle crashes. 
The National Highway Traffic Safety Administration was pleased to help sponsor this important effort. We appreciate the contributions of the chapter authors and acknowledge the leadership of the Southern Consortium for Biomechanics at the University of Alabama at Birmingham for conceptualizing and then bringing this important idea to a successful completion.

Washington, DC, USA

Stephen A. Ridella 


\section{Preface}

There's no question "Necessity is the Mother of Invention." And so it was in the late 1990s when to me, as Director and Principal Investigator of the University of Alabama at Birmingham's Injury Control Research Center (UAB-ICRC), Dame Necessity presented herself early one Monday morning. The ICRC's biomechanist suddenly and unexpectedly accepted a position elsewhere. My initial thoughts (following a fleeting assessment of the pros and cons of flinging myself from the top of our parking deck) involved trying to figure out how to turn this mini-catastrophe into something positive. Then, almost magically, a goal I long believed in became worth trying. I recalled a familiar political admonition: Never allow a crisis to go to waste when it is an opportunity to do some things you have never done before.

Failing to convince our biomechanist to change his mind, I decided on the spot to seize the opportunity to attempt to create something I had never before been in a position to try. I would establish a voluntary consortium of the brightest and best scientists from a few prestigious institutions whom I would (somehow) convince to work together collegially instead of competitively on the most pressing and important injury biomechanics problems of the day.

The caliber of person I needed to help me pull off this plan was not at the time at UAB. I must look elsewhere to find the leading scholar with the credentials and experience to attract the kind of extraordinary scientists who would need to agree to become part of this consortium if it were to have even one chance in a hundred to succeed. The enterprise would require someone willing to risk, as I was, innovative thinking, and unorthodox practices. Based on years of experience, I understood if talented, high-profile scientists from other institutions were to gamble on my idea, I myself must be willing to occupy the place where predictable disfavor, even wrath, would be aimed if our venture should fail. Why wouldn't my university be skittish? The infrastructure of the model I had in mind would call on my university to share indirect dollars, the lifeblood of virtually all academic research settings. Still, given the lack of depth in injury biomechanics on our School of Engineering's bench during that era, I had little choice. I would ask forgiveness rather than seek permission. I believed a consortium would succeed and UAB's 
administrative hierarchy would eventually forgive us, even amid the predictable cacophony of murmured displeasure from accountants and grant managers who cared not a wit about the quality of the science, but only about the bottom line. I was not dissuaded. I know that success has many fathers. When we succeeded many would emerge to bask in the shared glory of having made it all possible. I also knew those tentative fathers were totally insulated against failure. If the experiment did not work, it would be entirely my fault.

The immediate objective was to identify and engage a highly regarded engineer with impeccable credentials to help establish what I envisioned becoming the Gold Standard motor vehicle crash injury biomechanics research initiative in the nation. I stress "initiative" because the model in my mind was not based on bricks and mortar. Rather, it was Gestalt-driven with the whole becoming greater than the sum of its parts. Experts working on research we mutually determined necessary would remain exactly where they were, in some of the finest university-based injury biomechanics laboratories throughout the country.

Soon I placed the first and one of the most important of all the phone calls that would be made on behalf of an idea that would come to be known as "The Southern Consortium for Injury Biomechanics." I contacted Dr. Barry S. Myers of Duke University, a highly regarded biomechanist. Dr. Myers had heard of me but that was about all. Still, he listened to what I had to offer: possible funding for a small scale injury biomechanics proposal to be included in our ICRC's forthcoming competitive renewal application. His acceptance of that funding opportunity paved the way for a collaboration that was quite unlike anything ever before attempted in the CDC-sponsored injury control research center program.

We developed a blueprint linking the UAB-ICRC with Dr. Myers' Biomechanics Engineering Group at Duke University. That was only Phase 1 of three distinct phases to the new collaborative relationship. Phases 1 and 2 were confined to the collaboration between the UAB-ICRC and Barry S. Myers' group at Duke. Phase 3 extended beyond the UAB-Duke nidus and, within a short period of time, was populated by a handful of equally well-known and well-regarded injury biomechanists from several other highly esteemed research institutions.

Our shared vision was bold: significantly reduce traffic fatalities and injuries by bringing together top scientists to conduct collaborative rather than competitive safety research. For all practical purposes, the approach we took had little reason to succeed. Traditionally, most scientists work in their own laboratories on specific aspects of large problems. Even with communication through published manuscripts and professional meetings, it can take years for important knowledge products to result in safety innovations. SCIB participants chose to cooperate to identify and define problems, select and engage the most qualified scientists to work on each aspect of each problem, and remain in touch in a constant, deliberate manner to provide regular feedback, input, ideas, and solutions to problems. Freed from the fear that revealing individual discoveries could threaten future funding, SCIB promoted a stimulating, creative environment. 
With shared commitment to the concept, we witnessed the emergence of loosely knit, discipline-driven project teams composed of prominent scientists who previously had been, at best, friendly competitors. In retrospect, it appears a primary reason the collaborations began to thrive was that collectively scientists had the resources and tools needed to address some of the most challenging injury biomechanics problems of the day. This unique multidisciplinary mix resulted in the teams enjoying stateof-the-art research capacity that facilitated rigorous investigation of a group of problems from a multiple scientific perspectives. This capacity yielded more complete understanding of the problems. Moreover it yielded applicable solutions. Unlike independent workers, the SCIB research teams had the ability to apply a spectrum of research tools and techniques to a broad range of vexing problems impacting both human and mechanical systems. The teams were fluid, so any given project could be staffed by experienced scientists whose skill sets were ideally matched to specific project requirements at particular times. This diverse supply of "big hitter" personnel is not typically found at a single institution. A reasonable analogy might be a professional sports all-star team. In retrospect, the comparison seems entirely apropos.

Between 2000 and 2009 SCIB research filled in critical knowledge gaps in the understanding of how the human body reacts to the rapid, destructive impact of a high-velocity crash. The SCIB's research portfolio focused on preventing injuries to the head, neck, and extremities in adults and in children. SCIB members appreciated that children are different and could not continue to be studied simply as "small adults." This served as the underlying inspiration for pioneering work on a digital pediatric crash dummy known as the Digital Child. It also lead to improving computer modeling of pediatric crash injuries through development of a comprehensive online pediatric biomechanics data archive that evaluates and documents the current state of the most relevant research as well as policies affecting the automobile industry.

Admittedly, my vision of this initiative eventually becoming the Gold Standard motor vehicle crash injury biomechanics research activity in the country proved overly ambitious. We did not attain it. We tried hard, did some exciting and outstanding work, and were quite productive. The taxpayers whose hard-earned dollars supported this effort received an enormous return on their investment including a lengthy list of significant successful projects resulting in important contributions to injury biomechanics, the simultaneous training of a new generation of injury scientists who were able to participate in these unique collaborative research projects and who were trained to carry on this work and, finally, this Archive and Textbook which is the overall effort's crowning achievement.

As it is formally referenced, Pediatric Injury Biomechanics: Motor Vehicle Crash Injury Research is designed to be updated continuously as research advances and new data emerge. It is intended to become an indispensible tool for research scientists, vehicle designers, and rule, policy, and decision makers working on to make the motor vehicle environment as safe as possible for children. 
From the outside looking in at the end results of this effort, the extent of the challenges overcome during this decade-long odyssey may be hard to see. To those of us who lived it (and survived it) memories of some of the more harrowing moments have been attenuated by time and the sheer joy of being able, at long last, to hold in our hands one of the first printed copies of a genuine labor of love. The Textbook's incubator, the Southern Consortium for Injury Biomechanics, grew from a mere idea in late 1999 and early 2000 into an engine of leadership in injury biomechanics research for the remainder of the decade.

In retrospect, there is no question the unconventional research alliance between 2 and eventually as many as 11 prestigious medical research universities represented the very best in innovative, strategic thinking and creative management. That SCIB came into existence at all reflects an unselfish willingness among this group of extraordinary scientists to work voluntarily in a manner that recognized the potential cost-effectiveness of collaboration while exploiting the enormous benefits for the field of injury biomechanics.

In the years since the SCIB was established in 2000, extramural funding for injury biomechanics research has become near nonexistent. Denied the financial resources to continue groundbreaking work together, SCIB leaders made an important decision: to identify a single area in which there was consensus regarding greatest need and greatest potential benefit. A thoughtful, deliberative process generated the concept, design, and name of SCIBs final effort, the Pediatric Injury Biomechanics: Motor Vehicle Crash Injury Research textbook.

A number of factors influenced the selection of the final project. For example, one of the National Highway Traffic Safety Administration's (NHTSA) highest priorities is child injury prevention in the automotive crash environment. Automobile and child restraint manufacturers around the world are working diligently to improve child safety in cars. Unfortunately, researchers report the lack of available, reliable data needed to predict pediatric occupant kinematics and mechanisms of injury, to determine appropriate injury criteria, to develop age appropriate crash test dummies, and to evaluate effectively the potential for injury to children in the automotive crash environment. Also the study of when, how, and why pediatric injuries occur is one of the most rapidly emerging areas of crash injury research. Little published data exist that describe the structural, material, and mechanical properties of children as they age. Consolidation and analysis of this information is intended to provide essential information needed by researchers working in the field of pediatric injury including those involved in rulemaking activities, injury criteria development, child dummy development, and child injury interventions development, all of which will markedly improve the motor vehicle safety effectiveness for the younger population. Consolidation of this information also will help avoid duplication of previous research and identify critical gaps in the data and areas for future research.

This Archive and Textbook is particularly responsive to the needs of the automotive safety community because it consolidates all publicly available pediatric injury biomechanics research in one place, making it easily accessible. The book also 
helps identify exactly what research needs to be done to address the remaining issues related to child safety in the automotive crash environment.

The data archive component should prove to be an invaluable tool that will assist in identification of gaps in research as well as provide insight regarding future research direction decisions. It is intended to be a dynamic, living document that will be updated with current research and advancements in pediatric injury biomechanics on a regular, on-going basis. It is our hope the Archive and Textbook quickly becomes the "go-to" Best Reference for the epidemiology of motor vehicle-related childhood injury data, pediatric anthropometry, pediatric biomechanical properties, tissue tolerance, and computational models.

The textbook is divided into three sections. The first is entitled Introduction and Scope of the Problem. It contains two chapters, leading with information on pediatric anthropometry. The second chapter is devoted to the epidemiology of motor vehicle crashes in which children were injured or killed. The book's second section is entitled Experimental Data and consists of four chapters. Together, they provide a critical review, analysis, and summary of experimental testing organized by body regions. These four chapters also address age-based material, physical properties, and structural properties organized by body regions. By title, Chap. 3 is "Experimental Injury Biomechanics of the Pediatric Extremities and Pelvis." Chapter 4 is "Experimental Injury Biomechanics of the Pediatric Head and Brain." Chapter 5 is "Experimental Injury Biomechanics of the Pediatric Neck," and Chap. 6 is "Experimental Injury Biomechanics of the Pediatric Thorax and Abdomen." The third section is entitled Computational Models and consists of a single, comprehensive chapter entitled "Pediatric Computational Models." It provides information describing models that are currently available and explains how they are being used. In addition it devotes considerable attention to innovative computational modeling techniques that can be used to improve efficiency and data analysis.

In closing I wish to offer my most profound thanks to Mr. Stephen A. Ridella and Dr. Erik G. Takhounts who are both affiliated with the National Highway Traffic Safety Administration (NHTSA) and who are respected scientists in their own right. Steve and Erik reviewed, edited, corrected, and ultimately gave their seal of approval to the textbook. The importance of their assistance and the contributions they made cannot be underestimated. And, of course, my sincere thanks to an impressive assemblage of topic-specific expert contributors who were invited to be part of this effort because of their professional experience and impeccable scientific reputations. The excellence of their science is reflected in the chapters of this book.

Finally, a few words about the extraordinary group of gifted scientists who are ultimately responsible for this landmark contribution to pediatric injury biomechanics coming to fruition. My cherished friends and colleagues, Dr. Jeff R. Crandall (UVA), Dr. Barry S. Myers (Duke University), Dr. David Meany (U. Penn), Dr. Bharat K. Soni, and Dr. David Littlefield (UAB) have done a remarkable job of writing topic-specific chapters and editing the work of other chapter contributors.

The final coeditor, Salena Zellers Schmidtke, a UAB School of Engineering Masters Degree recipient who is the founder, President, and CEO of Bioinjury 
LLC, of Alexandria, Virginia, has been the project's $C P U$. This amazing woman understood, embraced, and nurtured the project from the moment she learned of the idea and was offered the opportunity. Notwithstanding the enormous contributions of her coeditors and chapter contributors, there is consensus that this book would not have happened had it not been for her tenacity, her commitment, and her dedication to the field of injury biomechanics... and all that that implies. Being able to think of these people not only as colleagues but as friends is a distinct honor and privilege that I acknowledge with humble appreciation.

Birmingham, AL, USA

Philip R. (Russ) Fine 


\section{Acknowledgements}

The painful error of inadvertent omission is a risk associated with listing, by name, those persons who deserve being acknowledged for their labor on behalf of a worthy undertaking. In this particular instance we refer to important individual roles in an effort spanning several years that have culminated in publication of this Pediatric Injury Biomechanics Archive \& Textbook. But, it is a risk we must take. Thus, to any person whose name may have been unintentionally omitted, we sincerely apologize and ask, in advance, for your understanding and forgiveness.

At the onset we wish to thank and acknowledge United States Senator Richard Shelby, whose fundamental appreciation for the importance of injury biomechanics research, particularly that which is motor vehicle related, made the SCIB possible at all. Because of Senator Shelby's commitment to and efforts on behalf of highway and traffic safety, the University of Alabama at Birmingham was able to lead an effort resulting in the establishment of the Southern Consortium for Injury Biomechanics; engage a small group of highly regarded injury biomechanists, clinicians, and other associated scientists from some of the country's most prestigious institutions to work collaboratively on some of the most pressing injury biomechanics issues; conduct much-needed but previously unfunded or underfunded research; and, culminate more than a decade of enormous productivity by publication of this book. Thank you, Senator Shelby, for having gone "the whole nine yards," and then some.

We also acknowledge and thank the National Highway Traffic Safety Administration (NHTSA) and the Federal Highway Administration (FHWA) for their invaluable participation in the effort, both as prudent stewards of the taxpayers' dollars that underwrote the Southern Consortium's work, and for their technical guidance, input, and assistance with the publication of this textbook.

Also, we wish to thank and acknowledge UAB SCIB leadership and central office personnel. An expression of gratitude is due Dr. Jay Goldman, Dean Emeritus, UAB School of Engineering, Mr. Jeff Foster, SCIB Associate Director for Administration and Finance, Dr. Andrea Underhill, Ms. Gail Hardin, Ms. Joy Fleisher, Dr. Despina Stavrinos, and Ms. Crystal Franklin. We would be remiss if we failed to acknowledge and thank UAB School of Medicine leadership which includes the Office of the Vice President of Health Affairs and Dean, UAB School 
of Medicine; UAB Department of Medicine leaders such as Dr. Bill Koopman and Dr. Bob Kimberly and Dr. Lou Bridges. Dr. Koopman's vision, advocacy, and initial support coupled with Dr. Bridges' limitless encouragement and generous additional financial support helped sustain the SCIB's UAB component during some difficult and uncertain periods.

We also wish to acknowledge and thank Dr. Albert King, Distinguished Professor and Chair, Department of Biomedical Engineering, Dr. King-Hay Yang, Professor and Director of the Bioengineering Center, and Ms. Christina D. Wagner, all of whom are affiliated with Wayne State University's prestigious and highly regarded College of Engineering.

Finally we wish to thank and acknowledge our colleague and friend Dr. Russ Fine. It was he who envisioned the entity that came to be known as the Southern Consortium for Injury Biomechanics. It was he who was willing to take the chance to try something that had not been tried before. Because of Russ Fine's ability to see out of the box and take a chance on this new approach with UAB-ICRC's Southern Consortium for Injury Biomechanics (SCIB), the community of US biomechanics experts who can provide industry and government with guidance on design of safety equipment has increased tremendously. We cannot thank Russ enough.

Charlottesville, VA, USA

Jeff R. Crandall

Durham, NC, USA

Barry S. Myers

Philadelphia, PA, USA

David F. Meaney

Alexandria, VA, USA

Salena Zellers Schmidtke 


\section{Contents}

1 Pediatric Anthropometry …………………….................................

Kathleen D. Klinich and Matthew P. Reed

2 Epidemiology of Child Motor Vehicle Crash

Injuries and Fatalities.

Kristy B. Arbogast and Dennis R. Durbin

3 Experimental Injury Biomechanics of the Pediatric

Extremities and Pelvis

Johan Ivarsson, Masayoshi Okamoto, and Yukou Takahashi

4 Experimental Injury Biomechanics of the Pediatric

Head and Brain

Susan Margulies and Brittany Coats

5 Experimental Injury Biomechanics of the Pediatric Neck

Roger W. Nightingale and Jason F. Luck

6 Experimental Injury Biomechanics of the Pediatric

Thorax and Abdomen

Richard Kent, Johan Ivarsson, and Matthew R. Maltese

7 Pediatric Computational Models

Bharat K. Soni, Jong-Eun Kim, Yasushi Ito,

Christina D. Wagner, and King-Hay Yang

Index 



\section{Contributors}

Kristy B. Arbogast, PhD Division of Emergency Medicine, Center for Injury Research and Prevention, The Children's Hospital of Philadelphia, Philadelphia, PA, USA

Brittany Coats, PhD Department of Mechanical Engineering, University of Utah, Salt Lake City, UT, USA

Jeff R. Crandall, PhD Nancy and Neal Wade Professor of Engineering and Applied Science, University of Virginia, Charlottesville, VA, USA

Dennis R. Durbin, MD, MSCE Division of Emergency Medicine, Center for Injury Research and Prevention, The Children's Hospital of Philadelphia, Philadelphia, PA, USA

Philip R. Fine, PhD, MSPH The Southern Consortium for Injury Biomechanics, UAB School of Medicine, The University of Alabama at Birmingham, Birmingham, AL, USA

Jay Goldman, DSc, PE The Southern Consortium for Injury Biomechanics, UAB School of Engineering, University of Alabama at Birmingham, Birmingham, AL, USA

Yasushi Ito, PhD Department of Mechanical Engineering, University of Alabama at Birmingham, Birmingham, AL, USA

Johan Ivarsson, PhD Biomechanics Practice, Exponent, Inc., Phoenix, AZ, USA

Richard Kent, PhD Center for Applied Biomechanics, University of Virginia, Charlottesville, VA, USA

Jong-Eun Kim, PhD Department of Mechanical Engineering, University of Alabama at Birmingham, Birmingham, AL, USA

Kathleen D. Klinich, PhD Biosciences Group, University of Michigan Transportation Research Institute, Ann Arbor, MI, USA 
Jason F. Luck Department of Biomedical Engineering, Pratt School of Engineering, Duke University, Durham, NC, USA

Matthew R. Maltese, MS Children's Hospital of Philadelphia, Philadelphia, PA, USA

Susan Margulies, PhD Department of Bioengineering, University of Pennsylvania, Philadelphia, PA, USA

David F. Meaney, PhD Department of Bioengineering, University of Pennsylvania, Philadelphia, PA, USA

Barry S. Myers, MD, PhD, MBA Department of Biomedical Engineering, Duke University, Durham, NC, USA

Roger W. Nightingale, PhD Department of Biomedical Engineering, Pratt School of Engineering, Duke University, Durham, NC, USA

Masayoshi Okamoto Honda R\&D Co. Ltd, Tochigi, Japan

Matthew P. Reed, PhD Biosciences Group, University of Michigan Transportation Research Institute, Ann Arbor, MI, USA

Stephen A. Ridella Director, Office of Applied Vehicle Safety Research, National Highway Traffic Safety Administration, United States Department of Transportation, Washington, DC, USA

Salena Zellers Schmidtke, MS, BME The Southern Consortium for Injury Biomechanics BioInjury, LLC Alexandria, VA, USA

Bharat K. Soni, PhD Department of Mechanical Engineering, University of Alabama at Birmingham, Birmingham, AL, USA

Yukou Takahashi Honda R\&D Co. Ltd, Tochigi, Japan

Erik G. Takhounts, PhD Human Injury Research Division, National Highway Traffic Safety Administration, U.S. Department of Transportation, Washington, DC, USA

Christina D. Wagner, PhD Computational Biomechanics, Biomedical Engineering, Wayne State University, Detroit, MI, USA

King-Hay Yang, PhD Computational Biomechanics, Biomedical Engineering, Wayne State University, Detroit, MI, USA 